\title{
Volcanic smog and cardiometabolic health: Hawaiian hypertension?
}

\author{
Robert D. Brook MD ${ }^{1}$ (D) | Jeffery R. Brook PhD ${ }^{2}$ | Elizabeth K. Tam MD \\ ${ }^{1}$ Division of Cardiovascular Medicine, University of Michigan, Ann Arbor, Michigan \\ ${ }^{2}$ Dalla Lana School of Public Health, University of Toronto, Toronto, Ontario \\ ${ }^{3}$ Department of Medicine, University of Hawai'i John A. Burns School of Medicine, Honolulu, Hawaii
}

Correspondence

Robert D. Brook, MD, Division of Cardiovascular Medicine, University of Michigan, Ann Arbor, MI.

Email: robdbrok@umich.edu

The eruption during May 2018 of the Kīlauea volcano in Hawai'i drew international attention to this spectacular force of nature. Modern technology allowed the global public to marvel at the awe-inspiring grandeur of volcanos from the safety of their own homes. However, Kìlauea also has a dark side. The current Lower Puna eruption, from dozens of fissures along the eastern rift zone, may be the most destructive volcanic event in the United States since the 1980 eruption of Mt. St. Helens. Over 700 homes and other properties were destroyed, roadways covered by lava and unique coastal features (eg, freshwater ponds) irrevocably spoiled. While only a handful of direct injuries from lava were reported, thousands of residents were forced to evacuate surrounding areas due to noxious levels of sulfur dioxide $\left(\mathrm{SO}_{2}\right)$. Moreover, as we will discuss in greater detail in later sections of this article, volcanos may also pose significant cardiometabolic health risks to the surrounding populations. We posit here that exposure to particulate air pollution derived from eruptions-volcanic smog (vog)-may contribute to high blood pressure (BP) and possibly to the development of the metabolic syndrome.

Kilauea is one of the most active volcanos in the world and has been continuously erupting since 1982 . Typically, 500-14 000 metric tons of $\mathrm{SO}_{2}$ are vented daily (https://vog.ivhhn.org/). ${ }^{1}$ The renewed eruption during 2018 substantially increased gaseous emissions which are capable of imparting serious health effects including mucosal irritation (eg, conjunctiva, nasopharynx), coughing, and the exacerbation of asthma. ${ }^{1}$ Fortunately, hazardous $\mathrm{SO}_{2}$ levels are typically limited to relatively nearby areas. Conversely, what is not widely appreciated (apart from most residents and some visitors to Hawai'i) is the markedly greater geographic scale and magnitude of the ensuing production of vog. Vog is an air pollution mixture composed chiefly of secondarily generated acidic aerosols in the fine particulate matter $<2.5 \mu \mathrm{m}\left(\mathrm{PM}_{2.5}\right)$ size range and comprised largely of sulfate species (eg, sulfuric acid). It is formed over hours-to-days when $\mathrm{SO}_{2}$ reacts in the presence of sunlight with oxygen, water vapor, and other gases in the atmosphere. Given the incessant activity of Kìlauea, there is often a background concentration of $\mathrm{PM}_{2.5}$ covering southwest Hawai'i Island due to meteorological and topographical conditions. ${ }^{1}$ Not surprisingly, however, $\mathrm{PM}_{2.5}$ levels increased dramatically and habitually blanketed much larger regions across Hawai'i Island during the spring and summer of 2018. The increase in vog can even impact other nearby more heavily populated islands (Maui, Oahu) depending upon prevailing wind conditions. What is visible to everyone is an undulating gray haze often more intense later in the afternoon due to landward sea-breezes. The miasma can become so severe as to obscure the normally stunning panorama (Figure 1). While vog is known to adversely influence the local economy, the less obvious potential consequences to public health should be of equal or even greater concern.

During 2018 daily $\mathrm{PM}_{2.5}$ levels increased 3- to 10 -fold above usual in parts of Hawai'i-ranging from 20 to $80 \mu \mathrm{g} / \mathrm{m}^{3}$. In many locations, they routinely exceeded World Health Organization (WHO) Air Quality Guidelines (AQG) $\left(<20 \mu \mathrm{g} / \mathrm{m}^{3}\right)$. The Air Quality Index even surpassed 150 on several occasions-a value deemed "unhealthy" even for people without pre-existing medical conditions (https://www.airnow.gov/). This magnitude of air pollution is a problem more typical for developing countries (eg, China and India), not a tropical paradise. What is perhaps most shocking; however, is that the public health ramifications for the more than 180000 residents and 1.8 million visitors to Hawai'i Island arriving each year from every corner of the world are less clear than the air itself. While several studies link vog to a worsening of respiratory ailments (eg, asthma exacerbations) (https://vog.ivhhn.org/), ${ }^{1}$ the wealth of research demonstrating numerous extra-pulmonary health effects from exposure to a similar air pollutant, anthropogenic $\mathrm{PM}_{2.5}$, should raise even greater concerns. 


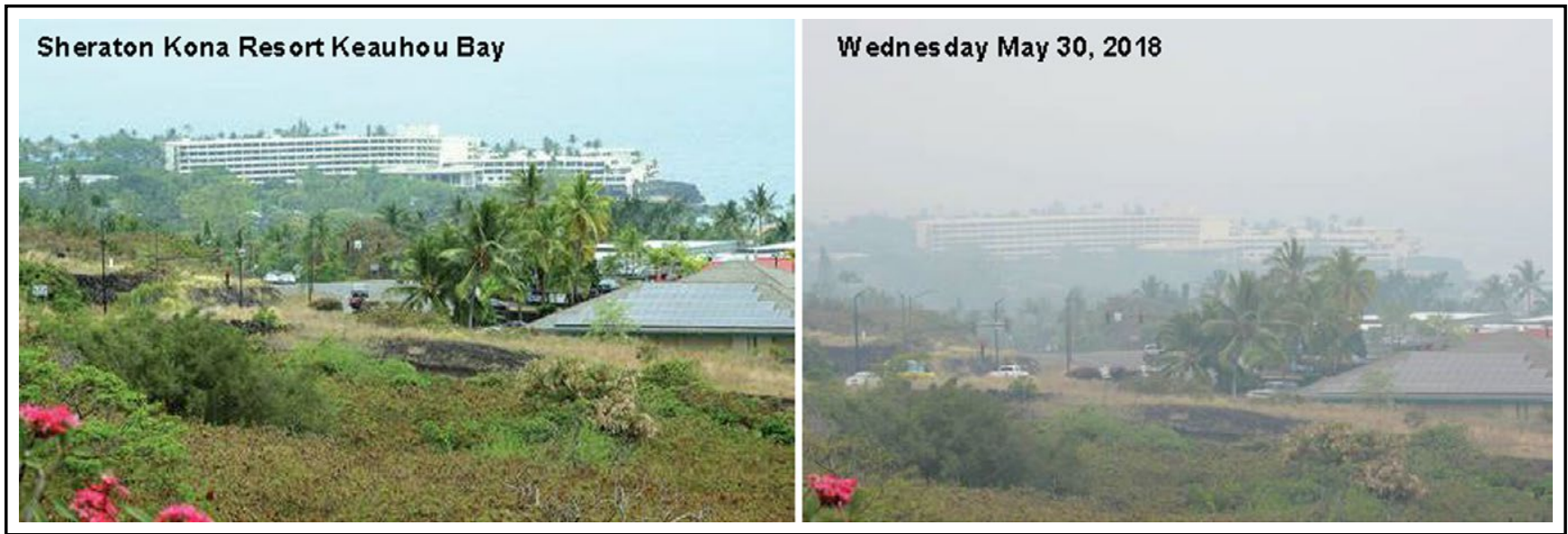

FIGURE 1 The visual obstruction of scenery caused by high levels of vog on the west coast of Hawai'i near Keauhou Bay south of KailuaKona. On May 30, 2018, the AQI was 154 and PM $_{2.5}$ levels reached approximately $80 \mu \mathrm{g} / \mathrm{m}^{3}$ (https://www.airnow.gov/) [Colour figure can be viewed at wileyonlinelibrary.com]

$\mathrm{PM}_{2.5}$ derived from fossil fuel combustion is the fifth leading risk factor for global mortality. Yet, what is often unappreciated is that cardiovascular diseases account for the majority (>60\%) of $\mathrm{PM}_{2.5}$-related deaths. ${ }^{2}$ Short-term exposures trigger myocardial infarctions, strokes, arrhythmias, heart failure, and cardiovascular mortailty. ${ }^{3} \mathrm{~A}$ $10 \mu \mathrm{g} / \mathrm{m}^{3}$ elevation in $\mathrm{PM}_{2.5}$ over a few days promotes a $1 \%-2 \%$ increase in these events. Living in persistently polluted locations over the long-term further amplifies these risks up to $10 \%$ per year. ${ }^{3}$ This increase in morbidity and mortality occurs even when $\mathrm{PM}_{2.5}$ levels are within WHO AQG. As such, both the American Heart Association and European Society of Cardiology have deemed $\mathrm{PM}_{2.5}$ as a causal risk factor for global cardiovascular diseases., ${ }^{3,4}$ In addition, we and others have shown that $\mathrm{PM}_{2.5}$ air pollution potentiates the development of cardiometabolic conditions-high BP, diabetes mellitus (DM), and atherosclerosis. ${ }^{3-16}$ Short-term exposures over a few hours to days significantly increase BP by several mechanisms. The pro-hypertensive response, typified by an increase in BP by $1-10 \mathrm{~mm} \mathrm{Hg}$ depending upon individual susceptibility and $\mathrm{PM}_{2.5}$ concentrations, is not limited to extremely high $\mathrm{PM}_{2.5}$ levels but occurs even within daily WHO AQG $\left(<20 \mu \mathrm{g} / \mathrm{m}^{3}\right) .^{8-11}$ Importantly, the elevation in BP has been shown to persist indefinitely-so long as air pollution levels remain high. Animal experiments add further mechanistic support that chronic exposures can promote long-lasting BP elevations. ${ }^{4,7}$ As such, mounting evidence supports that $\mathrm{PM}_{2.5}$ is a risk factor of global importance for the development of hypertension.,6,8-11 Moreover, there is a growing scientific literature that insulin resistance and DM are also provoked by air pollutants. ${ }^{12,13}$

Given the many linkages between man-made $\mathrm{PM}_{2.5}$ and cardiometabolic disorders, the following question thus arises: what about vog? Do particles comprised largely of sulfuric acid but less enriched in other toxic components (eg, metals, combustion-related organic species) ${ }^{1}$ present similar cardiometabolic risks? If we consider all fine particles regardless of their chemistry potentially harmful on a concentration (per mass/cubic meter) basis, in accordance with contemporary scientific practice, ${ }^{2,3}$ then there should indeed be a commensurate increase in $\mathrm{BP}$, insulin resistance, and cardiovascular events among those living or visiting the Hawaiian Islands who are exposed to vog. In support of this supposition, numerous studies have shown that the inhalation of aerosol particles regardless of source (rural and urban), size range (fine and coarse), and composition are capable of raising BP. ${ }^{3,8}$ Many environmental factors are known to increase $B P^{16}$ should vog be added to this growing list (eg, "Hawaiian hypertension"). ${ }^{11}$ If so, what is the total public health toll after accounting for these putative cardiometabolic effects given the dramatic increase in vog throughout 2018? What can (or should) the public do to protect themselves (eg, use indoor air filters or N95 respirators) during periods of heavy vog considering our current state of incomplete knowledge? How should healthcare providers advise patients who live in or wish to visit regions impacted by vog? Should individuals with hypertension and/or DM be concerned about vog worsening control of their BP and blood glucose?

These are just some of the many questions that, like the air itself in Hawai'i, await to be fully clarified. Here, we aim to raise awareness among the scientific and medical communities about vog as an issue not just of importance for Hawai'i, but for the world. Roughly, $5 \%-10 \%$ of the global population is impacted by a nearby volcano (tps://vog.ivhhn.org/). We further aim to draw attention to the urgent need for research to help inform public health and medical policies. Unlike anthropogenic $\mathrm{PM}_{2.5}$, surprisingly little is known about the health effects of vog, ${ }^{1}$ particularly in relation to cardiometabolic illnesses. What little data are available are mixed but suggest, like man-made air pollution, an association with increases in BP. ${ }^{17,18}$ Obviously, there is no effective way to regulate volcanic emissions to improve air quality, but studies can inform and encourage behavioral changes, public education, and policies to reduce exposure to air pollution of all sources. The most recent eruption of Kīlauea should serve as a wake-up call to jump-start cross-disciplinary research aiming to better understand the full health consequences of vog as well as to garner an evidence-base to guide rational public policy and 
individual-level strategies (eg, air filters) to help protect the millions of people living in and visiting areas impacted by vog. ${ }^{19}$

In closing, the public health issues surrounding vog will not vanish like a puff of smoke even after the most recent Kìlauea eruption completely abates. There are potential lingering effects in the population and there are always gaseous emissions resulting in low-tomoderate levels of $\mathrm{PM}_{2.5}$ across Hawai'i. Taking another lesson from anthropogenic air pollution, even low $\mathrm{PM}_{2.5}$ levels within annual AQG $\left(<12 \mu \mathrm{g} / \mathrm{m}^{3}\right)$ increase the risks for morbidity and mortality. ${ }^{3,4}$ The enduring risks from vog are therefore of special concern for the resident Native Hawaiian and Pacific Islanders, at-risk populations who disproportionately suffer from cardiometabolic risk factors such as obesity and DM (https://sites.ed.gov/aapi/data-and-statistics/) and who will face exposures in perpetuity. We believe much more effort is needed to elucidate the full extent of the potential health problems posed by vog. Environmental justice demands we focus greater attention on understanding and mitigating the adverse public health consequences.

\section{CONFLICT OF INTEREST}

The authors report no conflict of interest to disclose.

\section{ORCID}

Robert D. Brook iD https://orcid.org/0000-0002-8521-7262

\section{REFERENCES}

1. Tam E, Miike R, Labrenz S, et al. Volcanic air pollution over the island of Hawai'i: emissions, dispersal, and composition. Association with respiratory symptoms and lung function in Hawai'i Island school children. Environ Intern. 2016;92-93:543-552.

2. Cohen AJ, Brauer M, Burnett R, et al. Estimates and 25-year trends of the global burden of disease attributable to ambient air pollution: an analysis of data from the Global Burden of Diseases Study 2015. Lancet. 2017;389:1907-1918.

3. Brook RD, Newby DE, Rajagopalan S. Air pollution and cardiometabolic disease: an update and call for clinical trials. Am J Hypertens. 2017;31:1-10.

4. Rajagopalan SR, Al-Kindi SG, Brook RD. Air pollution and cardiovascular disease. J Am Coll Cardiol. 2018;72:2054-2070.

5. Pope CA, Turner MC, Burnett R, et al. Relationships between fine particulate matter air pollution, cardiometabolic disorders, and cardiovascular mortality. Circ Res. 2015;116:108-115.
6. Munzel T, Sorensen M, Gori T, et al. Environmental stressors and cardio-metabolic disease: part 1: epidemiologic evidence supporting a role for noise and air pollution and effects of mitigation strategies. Eur Heart J. 2017;38:550-556.

7. Munzel T, Sorensen M, Gori T, et al. Environmental stressors and cardio-metabolic disease: part II: mechanistic insights. Eur Heart J. 2017;38:557-564.

8. Giorgini P, Di Giosia P, Grassi D, Rubenfire M, Brook RD, Ferri C. Air pollution exposure and blood pressure: an updated review of the literature. Curr Pharm Design. 2015;22:28-51.

9. Liang R, Zhang B, Zhao X, et al. Effect of exposure to PM2.5 on blood pressure: a systematic review and meta-analysis. J Hypertens. 2014;32:2130-2140.

10. Yang BY, Qian Z, Howard SW, et al. Global association between ambient air pollution and blood pressure: a systematic review and meta-analysis. Environ Pollut. 2018;235:576-588.

11. Sanidas E, Papadopoulos DP, Grassos H, et al. Air pollution and arterial hypertension. A new risk factor is in the air. J Am Soc Hypertens. 2017;11:709-715.

12. Eze IC, Hemkens LG, Bucher HC, et al. Association between ambient air pollution and diabetes mellitus in Europe and North America: systematic review and meta-analysis. Environ Health Perspect. 2015;123:381-389.

13. Bowe B, Xie Y, Li T, Yan Y, Xian H, Al-Aly Z. The 2016 global and national burden of diabetes mellitus attributable to $\mathrm{PM}_{2.5}$ air pollution. Lancet Planet Health. 2018;2:e301-e312.

14. Rajagopalan S, Brook RD. Air pollution and type II diabetes: mechanistic insights. Diabetes. 2012;61:3037-3045.

15. Rao X, Montresor-Lopez J, Puett R, Rajagopalan S, Brook RD. Ambient air pollution: an emerging risk factor for diabetes mellitus. Curr Diab Rep. 2015;15:603.

16. Sharma P, Brook RD. Echoes from Gaea, Poseidon, Hephaestus, and Prometheus: environmental risk factors for high blood pressure. J Hum Hypertens. 2018;32:594-607.

17. Chow CD, Grandinetti A, Fernandez E, et al. Is volcanic air pollution associated with decreased heart-rate variability? Heat Asia. 2010;2:36-41.

18. Longo BM. Adverse health effects associated with increased activity at Kilauea volcano: a repeated population-based survey. ISRN Public Health. 2013;2013:1-10. Article ID 475962.

19. Brook RD, Newby DE, Rajagopalan S. The global threat of outdoor ambient air pollution to cardiovascular health. Time for intervention. JAMA Cardiol. 2017;2:353-354.

How to cite this article: Brook RD, Brook JR, Tam EK.

Volcanic smog and cardiometabolic health: Hawaiian hypertension? J Clin Hypertens. 2019;21:533-535. https:// doi.org/10.1111/jch.13500 